\title{
Brain and skeletal muscle bioenergetic failure in familial hypobetalipoproteinaemia
} Raffaele Lodi, Rita Rinaldi, Antonio Gaddi, Stefano Iotti, Roberto D’Alessandro,
Nicoletta Scoz, Maurizio Battino, Valerio Carelli, Giuseppe Azzimondi, Paolo Zaniol,
Bruno Barbiroli
Cattedra di

Biochimica Clinica, Dipartimento di Medicina Clinica e Biotecnologia Applicata "D Campanacci", Universita' di Bologna, Via Massarenti 9, 40138 Bologna, Italy

R Lodi

S Iotti

B Barbiroli

Centro Aterosclerosi

"Giancarlo

Descovich",

Dipartimento di

Medicina Clinica e

Biotecnologia

Applicata "D

Campanacci"

A Gaddi

N Scoz

Istituto di Neurologia, Università di Bologna

R Rinaldi

$R$ D'Alessandro

V Carelli

G Azzimondi

Istituto di Biochimica, Università di Ancona

M Battino

Istituto di Radiologia,

Univerista' di Modena,

Italy

P Zaniol

Correspondence to:

Dr Raffaele Lodi, MRC

Biochemical and Clinical,

Magnetic Resonance Unit,

Oxford Radcliffe Hospital,

Oxford OX3 9DU, UK.

Received 23 July 1997

and in revised form

22 January 1997

Accepted 31 January 1997

\begin{abstract}
Objective-To determine whether a multisystemic bioenergetic deficit is an underlying feature of familial hypobetalipoproteinaemia.

Methods-Brain and skeletal muscle bioenergetics were studied by in vivo phosphorus MR spectroscopy ( $\left.{ }^{31} \mathrm{P}-\mathrm{MRS}\right)$ in two neurologically affected members (mother and son) and in one asymptomatic member (daughter) of a kindred with familial hypobetalipoproteinaemia. Plasma concentrations of vitamin $E$ and coenzyme $\mathbf{Q}_{10}\left(\mathrm{CoQ}_{10}\right)$ were also assessed.

Results-Brain ${ }^{31} \mathrm{P}$-MRS disclosed in all patients a reduced phosphocreatine (PCr) concentration whereas the calculated ADP concentration was increased. Brain phosphorylation potential was reduced in the members by about $40 \%$. Skeletal muscle was studied at rest in the three members and during aerobic exercise and recovery in the son and daughter. Only the mother showed an impaired mitochondrial function at rest. Both son and daughter showed an increased end exercise ADP concentration whereas the rates of postexercise recovery of PCr and ADP were slow in the daughter. The rate of inorganic phosphate recovery was reduced in both cases. Plasma concentration of vitamin $E$ and $\mathrm{CoQ}_{10}$ was below the normal range in all members.

Conclusions-Structural changes in mitochondrial membranes and deficit of vitamin $E$ together with reduced availability of $\mathrm{CoQ}_{10}$ can be responsible for the multisystemic bioenergetic deficit. Present findings suggest that $\mathrm{CoQ}_{10}$ supplementation may be important in familial hypobetalipoproteinaemia.
\end{abstract}

$(\mathcal{F}$ Neurol Neurosurg Psychiatry 1997;62:574-580)

Keywords: familial hypobetalipoproteinaemia; in vivo ${ }^{31} \mathrm{P}-\mathrm{MRS}$; coenzyme $\mathrm{Q}_{10}$

Familial hypobetalipoproteinaemia is an autosomal monogenic disorder in which plasma concentration of apolipoprotein B-100 (APOB) and low density lipoprotein cholesterol (LDL-C) is abnormally low. ${ }^{1}$ This disease can be associated with progressive spinocerebellar ataxia, dementia, peripheral neuropathy, retinitis pigmentosa, fat malabsorption, acantocytosis, and low plasma content of vitamin
E. ${ }^{2}$ Neuromuscular manifestations can be found in heterozygotes, whereas haematological and gastrointestinal disorders are rare. ${ }^{2}$

The pathogenesis of this disorder is not yet fully understood. However, neurological symptoms and signs and the underlying neuropathological changes have been related to altered composition of cellular membranes due to the deficit of lipoprotein and vitamin $\mathrm{E}$ found in these patients ${ }^{34}$ and to the inability of the liver to incorporate vitamin $\mathrm{E}$ in the very low density lipoprotein and in LDL. ${ }^{5}$ A deficit of vitamin $E$ leads to an excessive lipid peroxidation with production of lipid peroxyl radicals which in turn can result in damage to cell membranes $^{36}$ as well as proteins and DNA. ${ }^{78}$ Therefore, it is conceivable that by different mechanisms, the damage due to free radicals results in an impairment of mitochondrial functionality and ATP production..$^{9-12}$

Tissue bioenergetics can be assessed in vivo by phosphorus magnetic resonance spectroscopy ( $\left.{ }^{31} \mathrm{P}-\mathrm{MRS}\right)$, the only available noninvasive method that gives precise information on the efficiency of ATP production and the extent to which oxidative metabolism meets the bioenergetic needs of cell function.

The aim of this study was to investigate by in vivo ${ }^{31} \mathrm{P}$-MRS whether a multisystemic defect of tissue bioenergetics is an underlying feature of the neurological disorders found in patients with a deficit of APO-B.

In view of the antioxidant role of vitamin $E$ and the bioenergetic and antioxidant functions of $\mathrm{CoQ}_{10,}{ }^{713}$ we also assessed the plasma concentrations of vitamin $\mathrm{E}$ and $\mathrm{CoQ}_{10}$.

\section{Patients and methods}

PATIENTS AND LABORATORY DATA

Figure 1 shows the family pedigree. Subjects with LDL-C concentration below the fifth percentile of values for age and sex matched local populations ${ }^{14}$ were classified as affected by hypobetalipoproteinaemia, according to published criteria. ${ }^{1215}$ Three members of the family with hypobetalipoproteinaemia, two neurologically affected, with LDL-C lower than the fifth percentile (II-5 and III-2), and one asymptomatic, with LDL-C between the fifth and the tenth percentile (III-3), underwent the in vivo study of energy metabolism of both brain and skeletal muscle. The fourth asymptomatic subject (III-5), with hypobetalipoproteinaemia (LDL-C concentration below the fifth percentile), did not consent to MRS examination. 

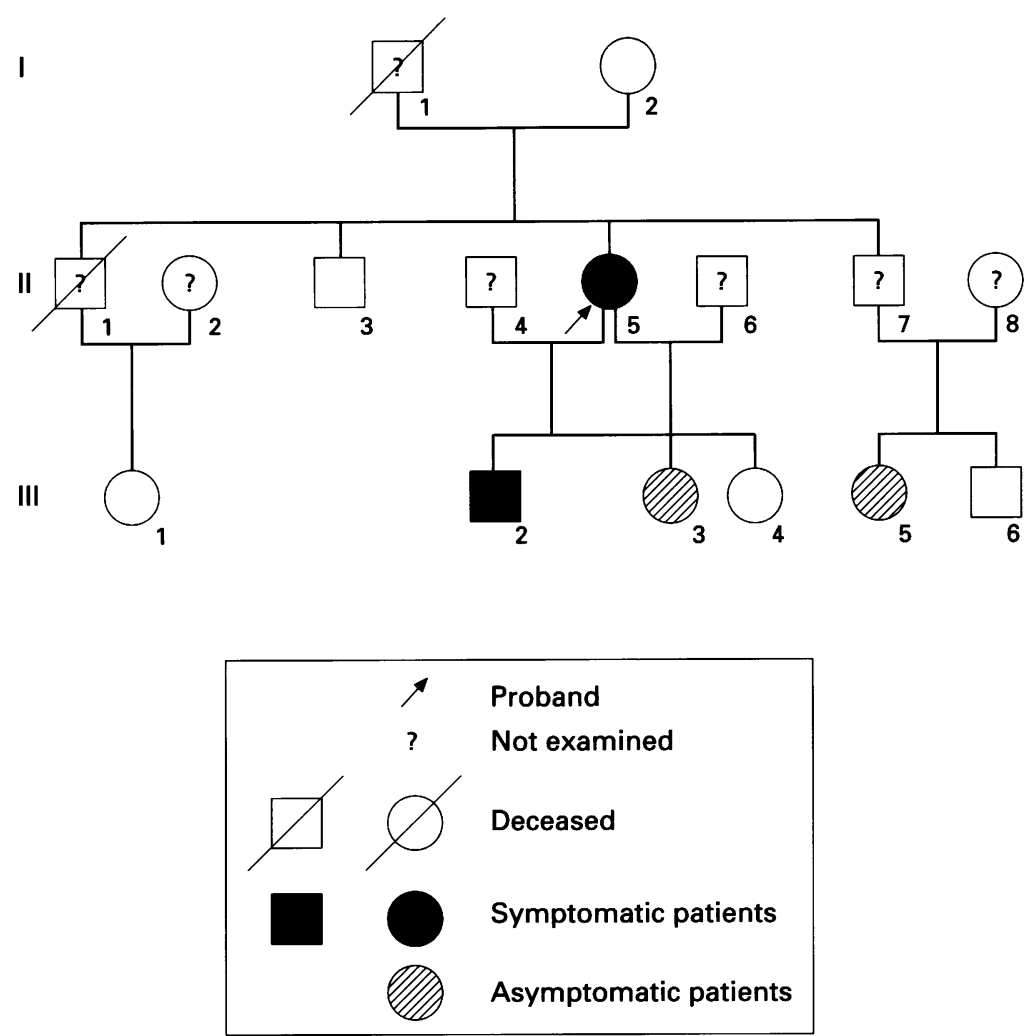

Figure 1 Pedigree of the family with familial hypobetalipoproteinaemia.

Case II-5 (proband)

This $\mathbf{5 5}$ year old woman had a severe bilateral neurosensory hearing deficit which had developed in a few years after the age of 25 . From the age of 40 she showed difficulty in walking associated with tremors in the upper and lower limbs, tingling in the hands, and personality changes. At 46 mental deterioration and a pronounced spinocerebellar syndrome with ataxic-spastic gait were found on examination. She worsened slowly and, at 55, developed a sensory-motor polyneuropathy and became bedridden.

\section{Case III-2}

The 29 year old son of the above patient had a slow psychomotor development until 15, but no evident cognitive impairment in adulthood. When he was 17 he had a sudden loss of vision in the left eye and a bilateral optic disc oedema, followed by a bilateral atrophy of papilla. His visual acuity was very reduced in the left eye and normal on the right.

Case III-3

The 25 year old daughter of the proband was asymptomatic and normal on neurological examination.

Table 1 Lipid serum concentrations in three subjects studied

\begin{tabular}{llllllll}
\hline Case & $\begin{array}{l}\text { Age }(y) / \\
\text { Sex }\end{array}$ & $\begin{array}{l}\text { TC } \\
(m g / d l)\end{array}$ & $\begin{array}{l}L D L-C \\
(m g / d l)\end{array}$ & $\begin{array}{l}H D L-C \\
(m g / d l)\end{array}$ & $\begin{array}{l}T G \\
(m g / d l)\end{array}$ & $\begin{array}{l}\text { APO-A1 } \\
(m g / d l)\end{array}$ & $\begin{array}{l}\text { APO-B } \\
(m g / d l)\end{array}$ \\
\hline II-5 & $55 / \mathrm{F}$ & $127(<5)$ & $61(<5)$ & 53 & $64(<10)$ & 138 & $48(<5)$ \\
III-2 & $29 / \mathrm{M}$ & $82(<5)$ & $29(<5)$ & 45 & $40(<10)$ & 140 & $47(<5)$ \\
III-3 & $25 / \mathrm{F}$ & $144(<5)$ & $81(<10)$ & 53 & $48(<10)$ & 151 & $42(<10)$ \\
\hline
\end{tabular}

The percentile values of serum lipid concentration are shown in parentheses only when in the bottom decile. Percentiles were determined for age and sex matched population of the same Italian region as the studied kindred. ${ }^{1461}$
In all three subjects serum biochemical tests, performed according to published methods, ${ }^{16}$ showed a significant decrease in serum content of total cholesterol (TC), LDL-C, triglycerides (TGs), and APO-B, whereas HDL-cholesterol (HDL-C) and APO-A1 concentrations were normal (table 1). Quality control was carried out by the World Health Organisation (WHO) Lipid Research Centre in Prague according to the procedure adopted for lipid clinics participating in the WHOERICA projects. ${ }^{17}$

The search for point mutations of $\mathrm{mtDNA}$ at positions 11778,3460 , and 14484 , pathogenic for Leber hereditary optic neuropathy, ${ }^{18}$ was negative in blood white cells from the proband and her son with bilateral optic atrophy.

Control subjects were 49 healthy volunteers. No athletes were included in the study. Control figures are presented as means (SD). A variable was considered normal when it fell within the range of mean controls $\pm 2 S D$.

Informed consent was obtained in all cases.

PHOSPHORUS MAGNETIC RESONANCE

SPECTROSCOPY ('P-MRS)

${ }^{31} \mathrm{P}-\mathrm{MRS}$ was performed with a GE 1.5 Tesla Signa system with a spectroscopy accessory using a surface coil provided by General Electrics and according to the quantification and quality assessment protocols defined by the EEC Concerted Research Project on Tissue Characterisation by MRS and MRI, COMAC-BEM II.1.3. ${ }^{19}$

Brain ${ }^{31} \mathrm{P}-\mathrm{MRS}$ was performed on the occipital lobes as reported. ${ }^{20}$ Spectra were acquired by a General Electrics $1.5 \mathrm{~T}$ Signa system with a spectroscopy accessory by a surface coil positioned on the occipital region after imaging the brain. The DRESS (depth resolved surface coil spectroscopy) localisation technique ${ }^{21}$ was used to avoid contribution to the signal by neck muscles, skin, and other interposed tissues. The stimulation-response sequence was repeated every five seconds. The flip angle in the selected volume was about $30^{\circ}$, and it was not necessary to introduce any correction for saturation effects due to repetition time. Four hundred free induction decays were accumulated to have a signal to noise ratio of nine to 12 for $\beta$-ATP. A computerised curve fitting program was used to quantify the individual peaks of the spectrum. By assuming a cytosolic ATP concentration of $3 \mathrm{mM}$, we calculated inorganic phosphate $(\mathrm{Pi})$ and phosphocreatine (PCr) concentrations, ADP concentration from the creatine kinase equilibrium, ${ }^{23}$ and the phosphorylation potential. ${ }^{24}$ We do not have absolute data on ATP concentration in patients with familial hypobetalipoproteinaemia. However, if ATP concentration were lower in these patients, the calculated ADP concentration would be even higher.

Muscle ${ }^{31} \mathrm{P}$-MRS was performed on the right gastrocnemius ${ }^{25}$ by the pulse and acquire technique (repetition time of five seconds), at rest, during in magnet aerobic isokinetic exercise, ${ }^{26}$ and during recovery from exercise. 
CASE II-5

Control
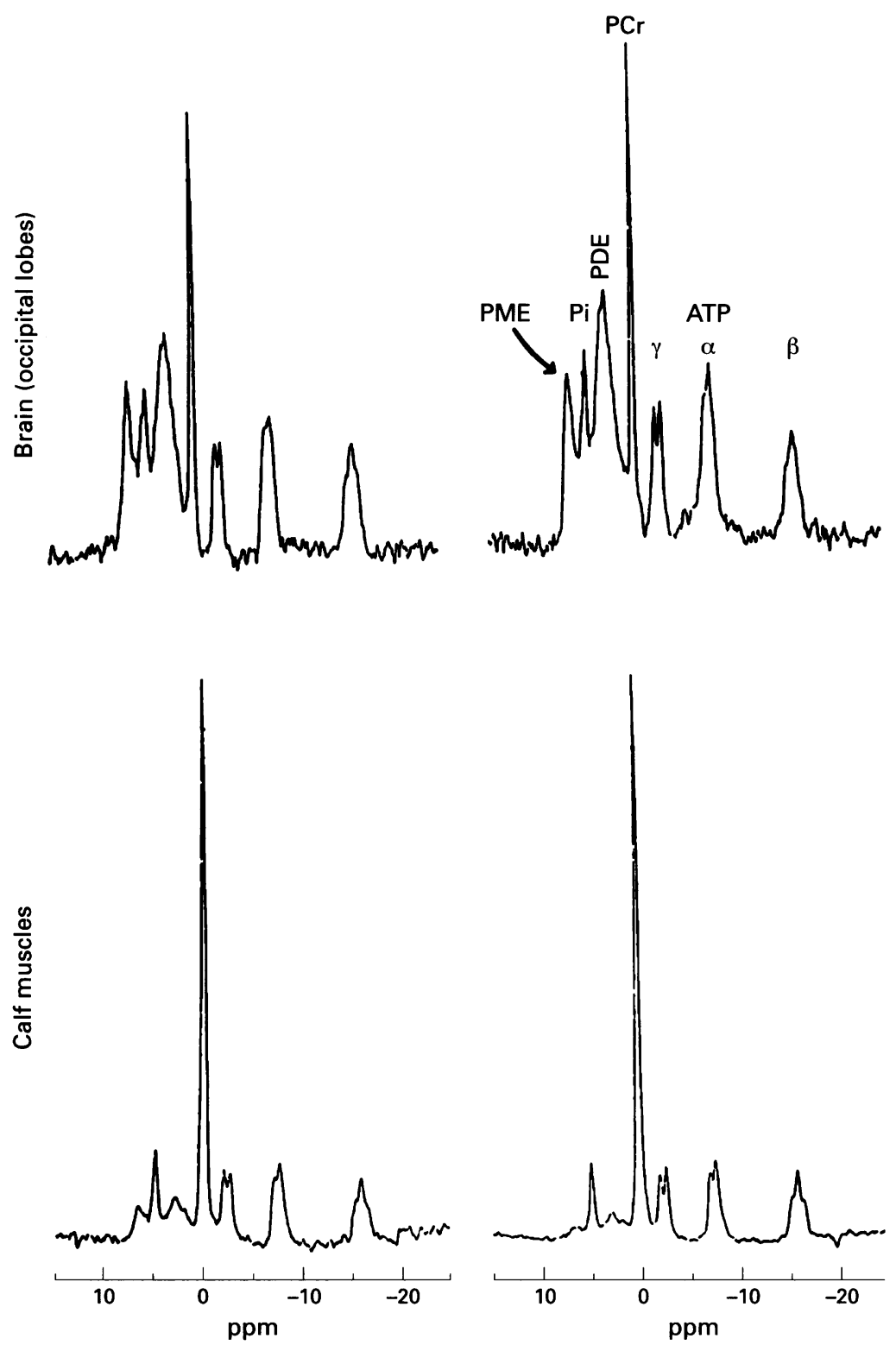

Figure 2 Upper section: ${ }^{31} P-M R S$ of occipital lobes from proband (II-5) compared with an age and sex matched normal volunteer. Lower section: ${ }^{31} P-M R$ spectra of resting calf muscle from the same subject and a sex and age matched normal volunteer. $P i=$ inorganic phosphate; $P C r=$ phosphocreatine; the phosphomonoester peak is located to the left of the Pi peak; the phosphodiester peak is located between the Pi and the PCr peaks.

Concentrations of $\mathrm{Pi}$ and $\mathrm{PCr}$ at rest were calculated assuming a cytosolic ATP concentration of $8.2 \mathrm{mM} .^{27}$ Cytosolic ADP concentration was calculated from the creatine kinase equilibrium..$^{28}$

The efficiency of mitochondrial ATP production was assessed by measuring the rate of

Table 2 Brain (occipital lobes) ${ }^{31} P-M R S$ data and mitochondrial function of three family members studied and 30 sex and age matched healthy subjects

\begin{tabular}{|c|c|c|c|c|c|}
\hline \multirow[b]{2}{*}{ Case } & \multicolumn{3}{|c|}{${ }^{31} P-M R S$ values } & \multicolumn{2}{|c|}{$\begin{array}{l}\text { Calculated mitochondrial } \\
\text { values }\end{array}$} \\
\hline & $\begin{array}{l}P C r \\
(m M)\end{array}$ & $\begin{array}{l}P i \\
(m M)\end{array}$ & $p H$ & $\begin{array}{l}A D P \\
(\mu M)\end{array}$ & $\begin{array}{l}\text { Phosphorylation } \\
\text { potential } \\
\left(\mathrm{mM}^{-1}\right)\end{array}$ \\
\hline $\begin{array}{l}\text { II-5 } \\
\text { III-2 } \\
\text { III-3 } \\
\text { Controls (mean (SD)) }\end{array}$ & $\begin{array}{l}3 \cdot 65^{\star} \\
3 \cdot 77^{\star} \\
3 \cdot 21^{\star} \\
4 \cdot 44(0 \cdot 28)\end{array}$ & $\begin{array}{l}1 \cdot 36 \\
1 \cdot 66^{\star} \\
1 \cdot 21 \\
1 \cdot 28(0 \cdot 12)\end{array}$ & $\begin{array}{l}7 \cdot 06 \\
7 \cdot 02 \\
7 \cdot 04 \\
7 \cdot 03(0.018)\end{array}$ & $\begin{array}{l}43^{\star} \\
37^{\star} \\
48^{\star} \\
28(2 \cdot 6)\end{array}$ & $\begin{array}{l}52^{\star} \\
52^{\star} \\
52^{\star} \\
83(7 \cdot 4)\end{array}$ \\
\hline
\end{tabular}

^Values 2 SD or more from the mean of normal controls. postexercise $\mathrm{ADP}$ and $\mathrm{PCr}$ recoveries which are entirely oxidative. ${ }^{28} 29$ The half life of ADP recovery was calculated from the slope of semilogarithmic plots. The rates of $\mathrm{PCr}$ resynthesis and of $\mathrm{Pi}$ recovery rates were calculated from the monoexponential equation best fitting the experimental points and reported as time constants (TCs). ${ }^{25}$

Intracellular $\mathrm{pH}$ was calculated from the chemical shift of $\mathrm{Pi}$ relative to $\mathrm{PCr} .{ }^{30}$ The chemical shift was carefully determined from the centre of the PCr peak to the centre of the Pi peak.

VITAMIN E AND COQ ${ }_{10}$ DETERMINATION Plasma vitamin $\mathrm{E}$ was estimated by high performance liquid chromatography (HPLC) using a fluorescence detector set at an excitation of $292 \mathrm{~nm}$ and an emission of $335 \mathrm{~nm}{ }^{31}$ Plasma $\mathrm{CoQ}_{10}$ was quantified, according to Takada et al, ${ }^{32}$ with reverse phase HPLC using an Erbasil C 18/M $150 \times 4.6 \mathrm{~mm}$ column and a mobile phase of propanol/methanol (20:80) with an isocratic $2 \mathrm{ml} / \mathrm{min}$ flow; column eluate was monitored at $275 \mathrm{~nm}$ in a Varian 2010 instrument. ${ }^{33} \mathrm{CoQ}_{10}$ data from patients were compared with the reference range used in our clinical laboratory $(0.693$ $\mathrm{mg} / \mathrm{l}$; mean of 86 reference subjects).

\section{Results}

Figure 2 shows the ${ }^{31} \mathrm{P}-\mathrm{MR}$ spectra obtained from the occipital lobes of case II-5 and an age and sex matched control. The resonance peak of $\mathrm{PCr}$ was reduced in this patient, whereas the $\beta$-ATP peaks were of the same intensity. Concentration of $\mathrm{PCr}$ was also significantly reduced in the proband's son and daughter (table 2). The asymptomatic daughter (case III-3) showed the lowest brain PCr concentration (table 2). Inorganic phosphate concentration was markedly increased in case III-2 whereas it was within the reference range in case II-5 and in case III-3. The ADP concentration was significantly increased in all three cases, showing the highest concentration in case III-3. The phosphorylation potential was reduced to $63 \%$ of the mean control value in all three cases.

Figure 2 also shows the spectra of resting calf muscles from case II- 5 and an age and sex matched control. This patient showed a significant increase in $\mathrm{Pi}$ concentration whereas both $\mathrm{PCr}$ concentration and cytosolic $\mathrm{pH}$ were normal (table 3). On the other hand, cases III2 and III-3 showed MRS data of resting calf muscles within the normal range (table 3 ). Only cases III-2 and III- 3 exercised inside the magnet. In both cases the end exercise $\mathrm{PCr}$ concentration was about $50 \%$ of the resting content. Ten normal volunteers were asked to exercise to deplete $\mathrm{PCr}$ to about the same concentration as the two patients (table 3). Despite the same metabolic activation, both cases showed a much higher end exercise cytosolic pH (table 3 ). The ADP concentration at the end of exercise was significantly above normal control values (table 3 ). The rate of ADP postexercise recovery was signifi- 
Table $3{ }^{31} P-M R S$ data of calf muscle at rest, at the end of exercise, and during the subsequent recovery of three family members studied and 49 normal sex and age matched healthy controls

\begin{tabular}{|c|c|c|c|c|c|c|c|c|c|c|}
\hline \multirow[b]{2}{*}{ Case } & \multicolumn{3}{|l|}{ Rest } & \multicolumn{3}{|l|}{ End exercise } & \multicolumn{4}{|l|}{ Recovery } \\
\hline & $\begin{array}{l}P C r \\
(m M)\end{array}$ & $\begin{array}{l}P i \\
(m M)\end{array}$ & $p H$ & $\begin{array}{l}P C r \\
(\%)\end{array}$ & $\begin{array}{l}A D P \\
(\mu M)\end{array}$ & $p H$ & pHmin & $\begin{array}{l}t_{1} A D P \\
(s)\end{array}$ & $\begin{array}{l}T C P C r \\
(s)\end{array}$ & $\begin{array}{l}T C P i \\
\text { (s) }\end{array}$ \\
\hline $\begin{array}{l}\text { II-5 } \\
\text { III-2 } \\
\text { III-3 } \\
\text { Controls }\end{array}$ & $\begin{array}{l}30 \cdot 9 \\
25 \cdot 6 \\
26 \cdot 5\end{array}$ & $\begin{array}{l}6 \cdot 24^{\star} \\
4 \cdot 31 \\
4 \cdot 45\end{array}$ & $\begin{array}{l}7 \cdot 11 \\
7 \cdot 07 \\
7 \cdot 03\end{array}$ & $\begin{array}{l}\overline{49} \\
51\end{array}$ & $\begin{array}{c}\overline{100^{\star}} \\
90^{\star}\end{array}$ & $\begin{array}{l}\overline{6.95} \\
6.95\end{array}$ & $\begin{array}{l}\overline{6 \cdot 78} \\
6.79\end{array}$ & $\begin{array}{l}\overline{11} \cdot 1 \\
19 \cdot 3^{\star}\end{array}$ & $\begin{array}{l}\overline{28} \cdot 0 \\
43 \cdot 7^{\star}\end{array}$ & $\begin{array}{l}\overline{42} \cdot 9^{\star} \\
49 \cdot 8^{\star}\end{array}$ \\
\hline mean (SD) & $27.9+(1.94)$ & $3.86+(0.49)$ & $7.07 \dagger(0.021)$ & $50 \cdot 4 \ddagger(2 \cdot 81)$ & $58 \ddagger(13 \cdot 5)$ & $6.84 \ddagger(0.07)$ & $6.85 \$(0.04)$ & $10.8+(3.62)$ & $29 \cdot 39(4 \cdot 57)$ & $30 \cdot 19(4 \cdot 98)$ \\
\hline
\end{tabular}

*Values 2 SD or more from the normal controls mean

$\$ 49$ controls; $¥ 10$ controls who reached an end exercise $\mathrm{PCr}$ depletion of $50.4(2.81) \%$ of the resting value; $\$ 10$ controls who reached an end exercise pH of 6.95 $(0.03)$; $\$ 10$ controls who reached a minimum $\mathrm{pH}$ during recovery of $6.79(0.09)$.

Case II -5 was not able to exercise properly because of mental deterioration and motor impairment. TC = Time constant.

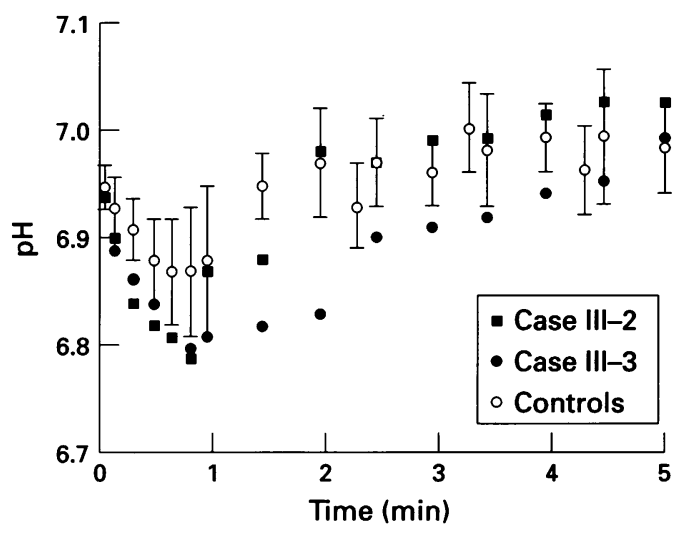

Figure 3 Time course of cytosolic pH recovery from exercise in cases III-2 (solid squares) and III-3 (solid circles) compared with 10 sex and age matched controls (open circles) that reached a similar cytosolic pH (6.95 (0.03)) at the end of exercise. Control data are shown as means (SD).

cantly reduced only in case III-3. In view of the influence of the minimum $\mathrm{pH}$ after exercise on the rate of $\mathrm{PCr}$ and $\mathrm{Pi}$ recovery, ${ }^{25}$ patients were compared with 10 normal controls who reached a similar postexercise minimum $\mathrm{pH}$. These experimental conditions render precise information on the functionality of mitochondria respiration independently of muscle mass, fibre type, and mitochondria density. ${ }^{34}$ The $\mathrm{PCr}$ recovery rate was normal in case III-2 and significantly slow in case III-3. In both cases the rate of postexercise Pi recovery showed a significant reduction (table 3 ).

Figure 3 illustrates the pattern of $\mathrm{pH}$ recovery in cases III-2 and III-3 and in 10 normal controls that reached a similar end exercise intracellular $\mathrm{pH}$. In the above subjects the $\mathrm{pH}$ overshooting tended to be faster and of higher degree than controls, although not significant.

The concentrations of plasma vitamin $\mathrm{E}$ and $\mathrm{CoQ}_{10}$ were below the normal range in all three subjects (table 4).

Table 4 Plasma coenzyme $Q^{\prime}$ and vitamin $E$ concentrations in three subjects studied

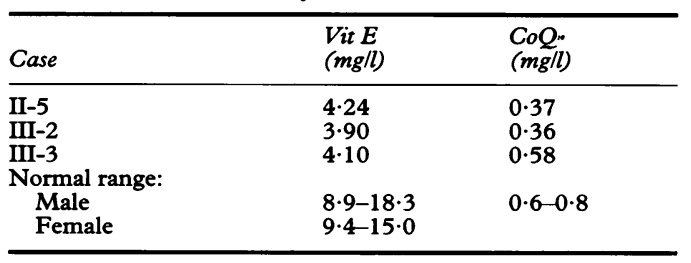

\section{Discussion}

The main finding of our study was a defective brain and skeletal muscle energy metabolism in two symptomatic relatives (cases II-5 and III-2) that fulfil the clinical and laboratory criteria for familial hypobetalipoproteinaemia and in one symptom free subject of the same kindred (case III-3) with a borderline low value of LDL-C. ${ }^{12}$ In all subjects we also found a reduced plasma content of $\mathrm{CoQ}_{10}$, implicating $\mathrm{CoQ}_{10}$ in the pathogenesis of the bioenergetic deficit.

Defective brain bioenergetics can be recognised by knowing the concentration of $\mathrm{PCr}$, $\mathrm{Pi}$, and ADP. ${ }^{35}$ Phosphocreatine was reduced in our three patients, case III-3 showing the lowest value. On the other hand, $\mathrm{Pi}$ showed a significant increase only in case III-2 (table 2). This result is difficult to understand as reciprocal alteration in $\mathrm{PCr}$ and $\mathrm{Pi}$ as a result of defective mitochondrial respiration would be expected, and we do not have any straightforward interpretation to offer. However, it is worthy to note that also in other conditions no reciprocal changes in $\mathrm{PCr}$ and $\mathrm{Pi}$ have been found. ${ }^{36-38}$

The ADP concentration was increased in all patients, showing the highest values in the symptom free daughter (case III-3). A high concentration of cytosolic free ADP, that exerts a hyperbolic control on oxidative phosphorylation, ${ }^{39}$ indicates that brain cells are operating nearer to the asymptote of the hyperbola and that they are less able to handle any further energy demand. The increase in $\mathrm{ADP}$ or $\mathrm{Pi}$ concentrations resulted in all three patients in a significant reduction of the cytosolic phosphorylation potential, an index of the cell's readily available free energy. ${ }^{24}$ This indicates an unstable metabolic condition of the brain of all subjects.

A bioenergetic deficit was also detected in the skeletal muscle (table 3 ). Case II-5 was examined only at rest due to the severity of her mental and motor impairment. Nevertheless, the ${ }^{31} \mathrm{P}$-MRS examination performed at rest was sufficient to disclose a failure of mitochondrial respiration as shown by increased concentration of $\mathrm{Pi}$. A high concentration of $\mathrm{Pi}$ indicates a severe impairment of muscle energy metabolism occurring in some disorders with primary and secondary mitochondrial dysfunction. ${ }^{4041}$ On the contrary, cases III-2 and III-3 showed all resting values within normal range (table 3). However, in cases III-2 
and III-3 we were able to investigate the metabolism of skeletal muscle under stressful conditions - that is, during exercise and recovery from exercise. In both cases the end exercise ADP concentration was higher than in controls who reached a similar PCr depletion at the end of exercise. The rise in ADP concentration stimulates mitochondria to operate closer to their maximal activity and may lead to normal mitochondrial ATP production in some neuromuscular disorders. ${ }^{42}{ }^{43}$ The stimulation of mitochondrial respiration by $\mathrm{ADP}$ resulted in a normal rate of mitochondrial ATP production in case III-2, as shown by a normal ADP and $\mathrm{PCr}$ recovery, but it could not drive the rate of mitochondrial phosphorylation to the normal range in case III-3 (table 3 ). The end exercise $\mathrm{pH}$ was somewhat higher in both cases than in matched controls that exercised to the same extent. Increased end exercise $\mathrm{pH}$ can be due to increased proton efflux or reduced lactate production. ${ }^{44}$ In both patients the proton efflux seems to be reduced-although not significantly-when compared with normal subjects with similar end exercise $\mathrm{pH}$ (fig 3). Therefore, a reduced contribution of anaerobic glycolysis is the more likely explanation for high $\mathrm{pH}$ at the end of exercise.

Postexercise recovery rate of $\mathrm{Pi}$ was slow in both patients compared with a group of normal subjects who reached a similar postexercise minimum $\mathrm{pH}$ (table 3 ). Changes in membrane composition, due to defective plasma transport of cholesterol and triglycerides $^{3}$ together with the membrane damage due to free radicals, ${ }^{45}$ may be responsible for the abnormal transport of both $\mathrm{Pi}$ and $\mathrm{H}^{+}$. In this light it is worth stressing that a slow rate of $\mathrm{Pi}$ and $\mathrm{H}^{+}$transport has been found in patients with Becker dystrophy and carriers ${ }^{46}$ and a slow rate of $\mathrm{H}^{+}$transport has been described in $m d x$ mice, ${ }^{47}$ being interpreted as a consequence of membrane malfunction.

Spinocerebellar syndrome with ataxia, peripheral neuropathy, and areflexia, are the main clinical features common to disorders such as abetalipoproteinaemia and hypobetalipoproteinaemia ${ }^{4}{ }^{45}$ cystic fibrosis, ${ }^{48}$ cholestatic liver disease, ${ }^{49}$ short bowel syndrome, ${ }^{50}$ and isolated vitamin $\mathrm{E}$ deficiency. ${ }^{51}$ In these diseases the content of vitamin $E$ is decreased in serum and in peripheral nerves. ${ }^{4}$ Although only the proband of our kindred showed a spinocerebellar syndrome whereas her son showed a bilateral optic atrophy-not described so far in association with hypobetalipoproteinaemia-and her daughter was asymptomatic, in all three cases we found a low plasma content of vitamin $\mathrm{E}$ as well as of $\mathrm{CoQ}_{10}$. We do not know the actual content of $\mathrm{CoQ}_{10}$ in the skeletal muscle of our patients. However, it has been shown that the plasma concentration reflects the tissue content of $\mathrm{CoQ}_{10} .{ }^{5253}$ The known functions of $\mathrm{CoQ}_{10}-$ that is, the electron transport in the inner mitochondrial membrane and-in its reduced form-antioxidant activity, ${ }^{73}$ lead us to hypothesise that the reduced plasma content of $\mathrm{CoQ}_{10}$ might play a part in the pathogenesis of neurological damage. There is evidence that $\mathrm{CoQ}_{10}$ is necessary for the regeneration of vitamin $\mathrm{E}$ from the $\alpha$-tochopheroxyl radical, whereas ubiquinol does not require vitamin $\mathrm{E}$ for its antioxidant activity. ${ }^{7}$ Coenzyme $Q_{10}$ is synthesised in all tissues by the mevalonate pathway ${ }^{754}$ and is transported in the bloodstream mainly bound to LDL, but its tissue redistribution from plasma is not yet established. ${ }^{7}$ It is also known that an increased availability of circulating $\mathrm{CoQ}_{10}$ ameliorates the efficiency of energy metabolism. ${ }^{55-57}$ This suggests that low $\mathrm{CoQ}_{10}$ could be responsible for a reduced efficiency of respiratory chain, or an increased oxidative stress of membranes, or both, possibly leading to neurological disturbances.

The different phenotype reported in apparent primary $\mathrm{CoQ}_{10}$ deficiency ${ }^{58}$ does not exclude a pathogenic relevance of the $\mathrm{CoQ}_{10}$ deficit. In fact, in primary mitochondrial disorders a similar bioenergetic deficit ${ }^{20}$ and even the same mtDNA mutation may result in different clinical expressions. ${ }^{59}$

We did not find a direct relation between the degree of energy metabolism failure and the clinical picture. In fact, the asymptomatic daughter (case III-3) had the most compromised energy metabolism. This is not a surprising finding as brain bioenergetic impairment has been described in patients affected by mitochondrial myopathy without any brain symptoms. ${ }^{2060}$ However, case III-3 is also the youngest of the examined patients and the time of exposure to the persistent energy metabolism defect may contribute to the development of neurological impairment.

Our results illustrate that a multisystem impairment of bioenergetics and a reduced rate of muscle $\mathrm{Pi}$ transport are biochemical features of familial hypobetalipoproteinaemia. They also show that a bioenergetic derangement can be present in asymptomatic patients. Three main factors may be responsible for the multisystem energy failure found in our patients: (1) structural changes of the inner mitochondrial membrane leading to spatial changes among respiration complexes thus interfering with the diffusion of mobile electron transporters in the mitochondrial inner membrane; (2) deficit of vitamin $\mathrm{E}$ leading to increased production of free radicals and consequent damage of mitochondrial membranes, DNA, or respiratory complexes; (3) reduced availability of $\mathrm{CoQ}_{10}$ in the inner mitochondrial membrane causing an impairment of oxidative phosphorylation.

The $\mathrm{CoQ}_{10}$ depletion, found in all the patients, suggests that $\mathrm{CoQ}_{10}$ supplementation may be important to halt further progression or to prevent neurological abnormalities in familial hypobetalipoproteinaemia.

The magnetic resonance system was a generous gift of the late Mr Enzo Ferrari, Maranello, Modena, who made this study possible. RL is recipient of a Telethon-Italy fellowship. 1 Malloy MJ, Kane JP. Hypolipidemia. Med Clin North Am
1982;66:469-84.
2 Kane JP, Havel RJ. Familial hypobetalipoproteinemia. In:
Scriver RC, Beaudet AL, Sly WS, Valle D, eds. The meta-
bolic basis of inherited disease (6th ed). USA: McGraw Hill, 1989:1151-3. 
3 Mars H, Lewis LA, Robertson AL, Butkus A, Williams GH. Familial Hypo-B-lipoproteinemia. A genetic disorder of lipid metabolism with nervous system involvement. Am ₹ Med 1969;46:866-900.

4 Traber MG, Sokol RJ, Ringel SP, Neville HE, Thellman CA, Kayden HJ. Lack of tocopherol in peripheral nerves of vitamin E-deficient patients with peripheral neuropathy. N Engl F Med 1987;317:262-5.

5 Kayden HJ, Traber MC. Absorbtion, lipoprotein transport, and regulation of plasma concentration of vitamin $E$ in humans. F Lipid Res 1993;34:343-58.

6 Kayden HJ. The neurologic syndrome of vitamin E deficiency: a significant cause of ataxia. Neurology 1993 43:2167-9.

7 Ernster L, Dallner G. Biochemical, physiological and medical aspects of ubiquinone function. Biochim Biophys Acta 1995;1271:195-204

8 Forsmark-Andree P, Ernster L. Evidence for a protective effect of endogenous ubiquinol against oxidative damage to mitochondrial protein and DNA during lipid peroxidato mitochondrial protein and DNA during lipid
tion. Mol Aspects Med 1994;15(suppl):73-81.

9 Kanno T, Utsumi T, Ide A, Takehara Y, Saibara T, Akiyama J, et al. Dysfunction of mouse liver mitochondria induced by $2,2^{\prime}$-azobis-(2-amidinopropane) dihydria induced by 2,2 -azobis-( 2 -amidinopropane) dihy-
drochloride, a radical initiator, in vitro and in vivo. Free drochloride, a radical initiat
Radic Res 1994;21:223-34.

10 Kristal BS, Park BJ, Yu BP. Antioxidants reduce peroxylmediated inhibition of mitochondrial transcription. Fre Radic Biol Med 1994;16:653-60.

11 Yen TC, King KL, Lee HC, Yeh SH, Wei YH. Age-dependent increase of mitochondrial DNA deletions togethe with lipid peroxides and superoxide dismutase in human liver mitochondria. Free Radic Biol Med 1994;16:207-14.

12 Shigenaga MK, Hagen T, Ames BN. Oxidative damage and mitochondrial decay in ageing. Proc Natl Acad Sci USA 1994;91:10771-8.

13 Battino $M$, Fato R, Parenti-Castelli G, Lenaz G. Coenzyme $\mathrm{Q}$ can control the efficiency of oxidative phosCoenzyme $Q$ can control the efficiency of oxid
phorylation. Int $\mathcal{F}$ Tissue Reac 1990;12:137-44.

14 Descovich GC, Dormi A, Minardi A, Benassi B, Cavina A et al. L'indagine di Brisighella. Studio dei fattori di rischio metabolici in un borgo dell'Emilia Romagna (Prima parte). Alimentazione e Dintorni, The Practitioner Edizion Italiana 1992;156(suppl):3-22.

15 Linton MF, Farese RV, Young SG. Familial hypobetalipoproteinemia. F Lipid Res 1993;34:521-41.

16 Gaddi A, Ciarrocchi A, Matteucci A, Rimondi S, Ravaglia G, Descovich G, Sirtori CR. Dietary treatment for familial hypercholesterolemia - differential effects of dietary soy protein according to the apolipoprotein $\mathrm{E}$ phenosoy protein according to the apolipopr

17 WHO-ERICA Research Group. The CHD risk-map of Europe. The 1 st report of the WHO-ERICA project. Eur Heart f 1988;9:1-36.

18 Harding AE, Sweeney MG, Govan GG, Riordan-Eva P. Pedigree analysis in Leber hereditary optic neuropathy
families with a pathogenic mtDNA mutation. Am 7 Hum families with a pathog
Genet $1995 ; 57: 77-86$.

19 EEC concerted research project. Quality assessment in in vivo NMR spectroscopy. Results of a concerted research project of the European Economic Community (6 papers). Magn Reson Imaging 1995;13:115-76.

20 Barbiroli B, Montagna P, Martinelli P, Lodi R, Iotti S, Cortelli $\mathrm{P}$, et al. Defective brain energy metabolism shown by in vivo ${ }^{31} \mathrm{P}$ MR spectroscopy in 28 patients with mitochondrial cytopathies. 7 Cereb Blood Flow Metab 1993;13:469-74.

21 Bottomly PA, Foster TH, Darrow RD. Depth-resolved surface-coil spectroscopy (DRESS) for in vivo ${ }^{1} \mathrm{H}$, "I $\mathrm{P}$, and 1:C NMR. F Magn Reson 1984;59:338-42.

22 Bottomly PA, Hardy CJ. Rapid, reliable in vivo assay of human phosphate metabolites by nuclear magnetic resohuman phosphate metabolites by

23 Chance B, Leigh Jr J, Kent J, McCully K, Nioka S, Clark $\mathrm{B}$, et al. Multiple controls of oxidative metabolism of living tissues as studied by "P MRS. Proc Natl Acad Sci USA 1986;83:9458-62.

24 Veech RL, Lawson JWR, Cornell NW, Krebs HA. Cytosolic phosphorylation potential. F Biol Chem 1979;254 6538-47.

25 Iotti S, Lodi R, Frassineti C, Zaniol P, Barbiroli B. In vivo assessment of mitochondrial functionality in human gastrocnemius muscle by $31 \mathrm{P}$ MRS. The role of $\mathrm{pH}$ in the evaluation of phosphocreatine and inorganic phosphate
recoveries from exercise. NMR Biomed 1993;6:248-53.

26 Zaniol P, Serafini M, Ferraresi M, Golinelli R, Bassoli P Canossi I, et al. Muscle "P-MR spectroscopy performed routinely in a clinical environment by a whole-body routinely in a clinical environment by a who
imager/spectrometer. Phys Med 1992;8:87-91.

27 Taylor DJ, Styles P, Matthews PM, Arnold DL, Gadian DG, Bore PJ, Radda GK. Energetics of human muscle: exercise-induced ATP depletion. Magn Reson Med 1986 3:44-54.

28 Arnold DL, Matthews PM, Radda GK. Metabolic recovery after exercise and the assessment of mitochondrial function in vivo in human skeletal muscle by means of P-31 NMR. Mag Reson Med 1984;1:307-15.

29 Kemp GJ, Taylor DJ, Radda GK. Control of phosphocreatine resynthesis during recovery from exercise in human skeletal muscle. NMR Biomed 1993;6:66-72.

30 Petroff OAC, Prichard JW, Behar KL, Alger JR, Shulman $\mathrm{T}$. Cerebral metabolism in hyper- and hypocarbia: "P $\mathrm{P}$ and ' $\mathrm{H}$ nuclear magnetic resonance studies. Neurology
1985;35:1681-8.
31 Lehmann J, Martin HL. Improved direct determination of alpha- and gamma-tocopherol in plasma and platelets in liquid chromatography, with fluorescence detection. Clin Chem 1982;28:1784-7.

32 Takada M, Ikenoya S, Yuzuriha T, Katayama K. Studies on reduced and oxidized coenzyme $Q$ (ubiquinones). on reduced and oxidized coenzyme $Q$ (ubiquinones). zyme $Q$ in mitochondria, microsome and plasma by high zyme $Q$ in mitochondria, microsome and plasma by high performance liquid

33 Battino M, Bargossi AM, Fiorella PL, Lenaz G. Plasma and platelet coenzyme Q10 in trained athletes. Giornale Italiano di Chimica Clinica 1990;15:347-51.

34 Barbiroli B, Iotti S, Lodi R. In vivo assessment of human skeletal muscle mitochondria respiration in health and disease. Mol Cell Biochem (in press)

35 Delivoria-Papadopulos $M$, Chance B. "P-NMR spectroscopy in the newborn. In: Guthrie RD, ed. Neonatal intensive care. New York: Churchill Livingstone, 1988 : 153-79.

36 Montagna P, Cortelli P, Monari L, Pierangeli G, Parchi P, Lodi $\mathrm{R}$, et al. "1P-magnetic resonance spectroscopy in migraine without aura. Neurology 1994;44:666-9.

37 Tracey I, Scott R, Thompson CH, Dunn JF, Barnes PRJ, Styles $\mathrm{P}$, et al. Brain abnormalities in Duchenne muscular dystrophy: a "P-magnetic resonance spectroscopy an neuropsychological study. Lancet 1995;345:1260-4.

38 Montagna P, Funicello R, Pierangeli G, Cortelli P, Lugaresi E, Zaniol P, Barbiroli B. Brain oxidative metabolism in Parkinson's disease studied by phosphorus 31 magnetic resonance spectroscopy. $\mathcal{F}$ Neuroimaging 1993; 3:225-8.

39 Chance B, Leigh Jr J, Clark BJ, Maris J, Kent J, Nioka S, Smith D. Control of oxidative metabolism and oxygen delivery in human skeletal muscle: a steady state analysis of the work/energy cost transfer function. Proc Natl Acad Sci USA 1985;82:8384-8.

40 Matthews PM, Allaire C, Shoubridge EA, Karpati G, Carpenter S, Arnold DL. In vivo muscle magnetic resonance spectroscopy in the clinical investigation of mitochondrial disease. Neurology 1991;41:114-20.

41 Lodi R, Montagna P, Iotti S, Zaniol P, Barboni P, Puddu P, Barbiroli $B$. Brain and muscle energy metabolism studied in vivo by "P-magnetic resonance spectroscopy in NARP

42 Taylor DJ, Kemp GJ, Woods CG, Edwards JH, Radda GK. Skeletal muscle bioenergetics in myotonic dystrophy. $\mathcal{F}$ Neurol Sci 1993;116:193-200.

$43 \mathrm{Kemp}$ GJ, Thompson CH, Taylor DJ, Hands LJ, Rajagopalan B, Radda GK. Quantitative analysis by ${ }^{31} \mathrm{P}$ MRS of abnormal mitochondrial oxidative in skeletal muscle during recovery from exercise. NMR Biomed 1993;6:302-10.

44 Kemp GJ, Taylor DJ, Styles P, Radda GK. The production, buffering and efflux of protons in human skeletal muscle during exercise and recovery. NMR Biomed 1993;6:73-83.

45 Muller DPR, Lloyd JK, Wolff OH. Vitamin E and neurological function. Lancet 1983;i:225-8.

46 Barbiroli B, Funicello R, Iotti S, Montagna P, Ferlini A, Zaniol P. "P-NMR spectroscopy of skeletal muscle in Becker dystrophy and DMD/BMD carriers. Altered rate of phosphate transport. $\mathcal{F}$ Neurol Sci 1992;109:188-95.

47 Dunn J, Tracey I, Radda G. A "P-NMR study of muscle exercise metabolism in mdx mice: evidence for abnormal pH regulation. F Neurol Sci 1992;113:108-13.

48 Elias E, Muller DPR, Scott J. Association of spinocerebellar disorders with cystic fibrosis or chronic childhood cholestasis and very low serum vitamin E. Lancet 1981; ii: $1319-21$.

49 Rosenblum JL, Keating JP, Presky AL, Nelson JS. A progressive neurologic syndrome in children with chronic gressive neurologic syndrome in children
liver disease. $N$ Engl $\mathcal{F}$ Med 1981;304:503-8.

50 Howard L, Ovesen L, Satya-Murti S, Chu R. Reversible neurological symptoms caused by vitamin $\mathrm{E}$ deficiency in a patient with short bowel syndrome. Am f Clin Nutr 1982;36:1243-9.

51 Gotoda T, Arita M, Arai H, Inoue K, Yokota T, Fukuo Y, et al. Adult-onset spinocerebellar dysfunction caused by a mutation in the gene for the a-tocopherol-transfer protein. N Engl f Med 1995;333:1313-8.

52 Karlsson J. Heart and skeletal muscle ubiquinone or $\mathrm{CoQ}_{1}$ as a protective agent against radical formation in man. In: Benzi G, ed. Advances in myochemistry. London: John Libbey Eurotext, 1987:305-18.

53 Karlsson J. Skeletal and blood $\mathrm{CoQ}_{10}$ in health and disease In: Lenaz $\mathrm{G}$, ed: Highlights in ubiquinone research. In: Lenaz G, ed: Highlights in ubiquin
London: Taylor and Francis, 1990:288-95.

54 Appelkvist EL, Aberg F, Guan Z, Parmryd I, Dallner G. Regulation of coenzyme Q biosynthesis. Molec Aspects Med 1994;15(suppl):37-46.

55 Ogasahara S, Yorifuji S, Nishikawa Y, Takahashi M, Wada $\mathrm{K}$, Hazama $\mathrm{T}$, et al. Improvement of abnormal pyruvate metabolism and cardiac conduction defect with coenzyme Q10 in Kearns-Sayre syndrome. Neurology 1985; 35:372-7.

56 Nishikawa Y, Takahashi M, Yorifuji S, Nakamura Y, Ueno $S$, Tarui $S$, et al. Long-term coenzyme $Q_{10}$ therapy for a mitochondrial encephalomyopathy with cytochrome oxidase deficiency: a "P NMR study. Neurology 1989; 39:399-403.

57 Lodi R, Iotti S, Scorolli L, Scorolli G, Bargossi AM, Sprovieri C, et al. The use of phosphorus magnetic resonance spectroscopy to study in vivo the effect of $\mathrm{CoQ}_{1}$ 
treatment in retinitis pigmentosa. Molec Aspects Med 1994;15(suppl):221-30.

58 Ogasahara S, Engel A, Frens D, Mack D. Muscle coenzyme $Q$ deficiency in familial mitochondrial encephalomyopathy. Proc Natl Acad Sci USA 1989;86: 2379-82.

59 DiMauro S, Moraes CT. Mitochondrial encephalomy-

60 Eleff S, Barker P, Blackband S, Chatham J, Lutz M, Johns
D, Bryan R. Phosphorus magnetic resonance spectroscopy of patients with mitochondrial cytopathies demonstrates decreased levels phosphocreatine. Ann Neurol 1990;27:626-30.

61 Descovich GC, Dormi A, Minardi A, Benassi B, Bonetti C, Ceredi $\mathrm{C}$, et al. L'indagine di Brisighella. Studio dei fattori di rischio metabolici in un borgo dell'Emilia Romagna (seconda parte). Alimentazione e Dintorni, The Practitioner Edizione Italiana 1992;167(suppl):3-22. 